\title{
Ridge splitting for horizontal bone augmentation with Guided Bone Regeneration (GBR) and simultaneous implant placement
}

\author{
Agarwal $\mathrm{N}^{1}$, Pai UY ${ }^{2}$, Rodrigues $\mathrm{SJ}^{3}$, Baral $\mathrm{S}^{4}$ \\ ${ }^{1}$ MDS, Prosthodontics and Implantology, Private Practitioner, Kathmandu, Nepal. \\ ${ }^{2}$ Associate Professor, Department of Prosthodontics, Manipal College of Dental Sciences, Mangalore, Manipal Academy \\ Of Higher Education, Karnataka, India. \\ ${ }^{3}$ Professor, Department of Prosthodontics, Manipal College of Dental Sciences, Mangalore, Manipal Academy of Higher \\ Education, Karnataka, India. \\ ${ }^{4}$ BDS, Private Practitioner, Kathmandu, Nepal.
}

\begin{abstract}
Horizontal lack of residual ridge width can complicate the implant procedures. Therefore, ridge construction prior to implant placement is a biomechanical requirement.Guided bone regeneration, bone grafting, alveolar ridge splitting and combinations of these techniques are used for the lateral augmentation of the alveolar ridge. The ridge splitting technique with simultaneous implant placement seems to be a minimally invasive treatment option for horizontal augmentation of narrow alveolar ridges with adequate vertical height. This paper thoroughly describes a segmental ridge splitting technique with both vertical and horizontal osteotomy cuts followed by the use of chisel and mallet to lateralise the buccal bone which was accompanied by GBR and simultaneous implant placement.
\end{abstract}

Key words: Ridge split; Inadequate ridge width; GBR

\section{Introduction}

Dental implants are one of the most predictable treatment options for the replacement of single missing tooth. ${ }^{1-4}$ However, inadequate width of the alveolar ridge remains a major limitation in ideal implant placement. Atrophy due to prolonged delay in the prosthetic rehabilitation, periodontal disease and trauma are contributors to insufficient horizontal ridge width. Ridge expansion using alveolar ridge splitting, autogenous bone grafting, Guided Bone Regeneration (GBR) or a combination of these methods have been suggested to regain the ridge

\section{Conflict of Interest: No}

*Corresponding Author
Dr. Nikita Agarwal
MDS, Prosthodontics, Private Practitioner,
Kathmandu, Nepal
Postal Address: Silver City, Kalikasthan, Kathmandu,
Nepal
E-mail: nikita0308@gmail.com

width prior to implant placement. ${ }^{5-6}$ Autogenous bone grafting for ridge expansion is a reliable method but has problems such as prolonged healing time, donor site morbidity and graft resorption associated with it. ${ }^{5,-8}$ However, ridge splitting along with Guided Bone Regeneration (GBR) and simultaneous implant placement is a viable alternative to gain ridge width in cases where the ridge height is adequate. ${ }^{9}$

The method of ridge splitting for root form implants was first put forth by Dr. Hilt Tatum in the 1970s. ${ }^{10}$ Tatum had developed instruments like D-shaped osteotomes and tapered channel formers to expand the resorbed residual ridge in horizontal dimension. This technique is suitable for horizontal deficiencies where the ridge width is between $3-6 \mathrm{~mm}$ with no need for vertical augmentation. The ridge split technique requires a minimum of $3 \mathrm{~mm}$ of bone width with at least $1 \mathrm{~mm}$ of cancellous bone between the two cortical plates to ensure a good blood 
supply and allow instrumentation. The alveolar ridge splits by inducing a controlled green stick fracture between the cortical plates. This space is slowly filled with new bone similar to healing of an extraction socket ${ }^{11}$. This technique can be done with hand instruments ${ }^{12}$, microsaw ${ }^{13}$, peizosurgery or an ultrasonic device $^{14}$. Osteotomes, screw spreaders or horizontal spreaders and chisels are used for lateral positioning of the buccal cortical plate. The acceptance of this technique is higher due to the reduced overall treatment time, decreased morbidityand increased bone compression and trabecular density ${ }^{15-17}$. The survival rates of implants inserted by this method is between $86 \%$ and $97 \%{ }^{13}$. However, a proper case selection is paramount in achieving surgical and prosthetic success.

The purpose of this paper is to describe a segmental ridge splitting technique with both vertical and horizontal osteotomy cuts followed by the use of chisel and mallet to lateralize the buccal bone. It was accompanied by GBR and simultaneous implant placement.

\section{Clinical Report}

A 22-year-old female patient presented with a missing tooth lost due to decay in the lower right back tooth region tooth number 45 since 2 years. The medical and family history was non- contributory. The patient had a history of orthodontic treatment completed 2 years back. Clinical and Radiographic findings revealed a thick gingival biotype and horizontal ridge deficiency with adequate vertical ridge height (Figure 1). Furthermore, a slight mesial drifting of tooth number 46 was noted. The radiographic examination done through Cone Beam Computed Tomography (CBCT) (Planmeca Promax Mid; Helsinki, Finland) showed that the available width of bone at $3 \mathrm{~mm}$ from the ridge crest was $4.2 \mathrm{~mm}$ and the available ridge height was $12 \mathrm{~mm}$. (Figure 2). The scan revealed adequate cancellous and cortical bone to perform a ridge splitting technique. Since, the patient opted for an implant supported prosthesis a ridge split technique with GBR and simultaneous implant placement was planned.

\section{Surgical Technique}

Prior to the surgical procedure, pre-operative prophylactic antibiotics and analgesic were prescribed and the patient was prepared in a sterile environment. The patient was made to rinse the mouth with $0.2 \%$ chlorhexidine (Hexidine, ICPA Health Products, India) solution for a minute pre-surgically. Local anesthesia was administered using $2 \%$ lidocaine with 1:200,000 epinephrine (Lox -2, Injections, Neon Laboratories, India) . A full thickness mucoperiosteal flap bucally and lingually was elevated following a mid-crestal incision (Figure 3). A horizontal osteotomy was obtained with the pilot drill. A microsaw handpiece (NSK SGO-E with $17^{\circ}$ horizontal reciprocating action, Japan) with a bur was used to enlarge the horizontal osteotomy mesiodistally. Two additional vertical cuts were created on the buccal cortical plate at the mesial and the distal end of the horizontal incisions. (Figure 4) Ridge split chisels and mallet (Dentium RS Kit, Korea) (Figure 5) of increasing sizes were engaged between the cortical plates to progressively lateralise the buccal plate. (Figure 6)

Sequential drilling was done under copious saline irrigation for implant bed preparation and an implant of dimensions $3.75 \mathrm{X} 11.5$ was placed simulateouslly at $35 \mathrm{Ncm}$. (MIS 7, MIS Implant Tecnologies, Israel). (Figure 7 and 8) The residual space between the two cortical plates were interposed with a xenograft material (Bio-Oss, Geistlich, Princeton, USA) (Figure 9) and covered with a resorbable PRF membrane obtained from the patient. (Figure 10) A close 
approximation was achieved with tension free simple interrupted sutures. (Figure 11)

The patient was prescribed analgesics and antibiotics post-operatively. The patient was advised to maintain a soft diet and to use the provisional prosthesis only when necessary. A $0.2 \%$ chlorhexidine gluconate mouth wash (Hexidine, ICPA Health Products, India) was prescribed for two weeks. The sutures were removed after 1 week and the implants were allowed to heal for 6 months prior to the fabrication of final prosthesis.

\section{Prosthetic Phase}

At the second stage surgery, a gingival former was left in place for 3 weeks to allow adequate tissue contouring (Figure 12). A polyether impression (Pentamix, 3M ESPE, Minnesota, USA) was recorded and abutment trial was done in the subsequent appointment. (Figure 13) A screw retained PFM crown having only centric point contacts and free of eccentric interferences was delivered to the patient. (Figure 14,15) A follow up X-Ray was taken at 6 months post op. (Figure 16)

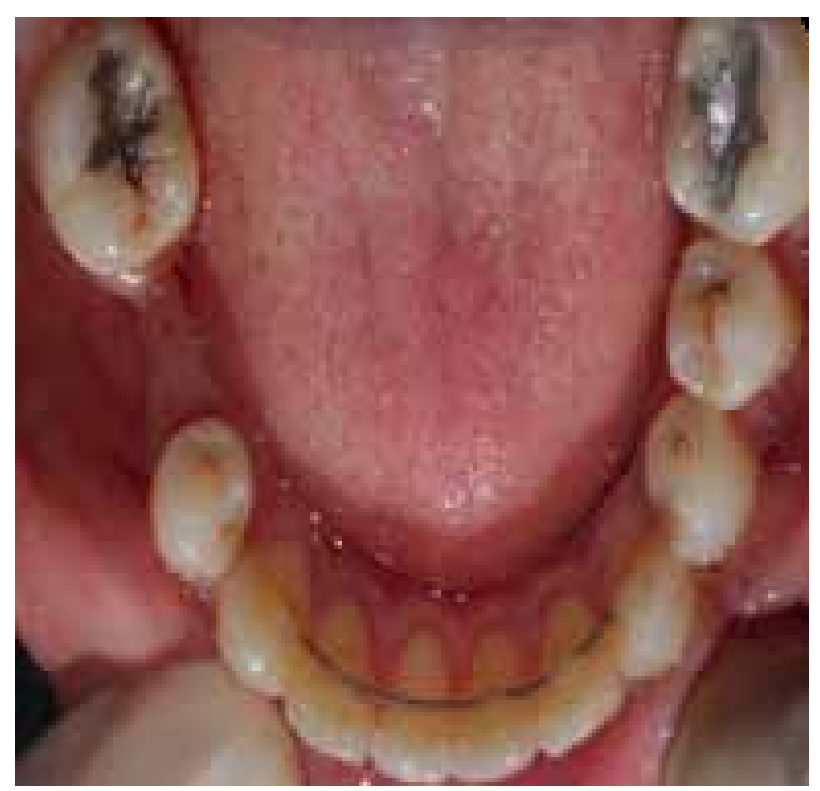

Figure 1: Pre-operative mandibular occlusal view

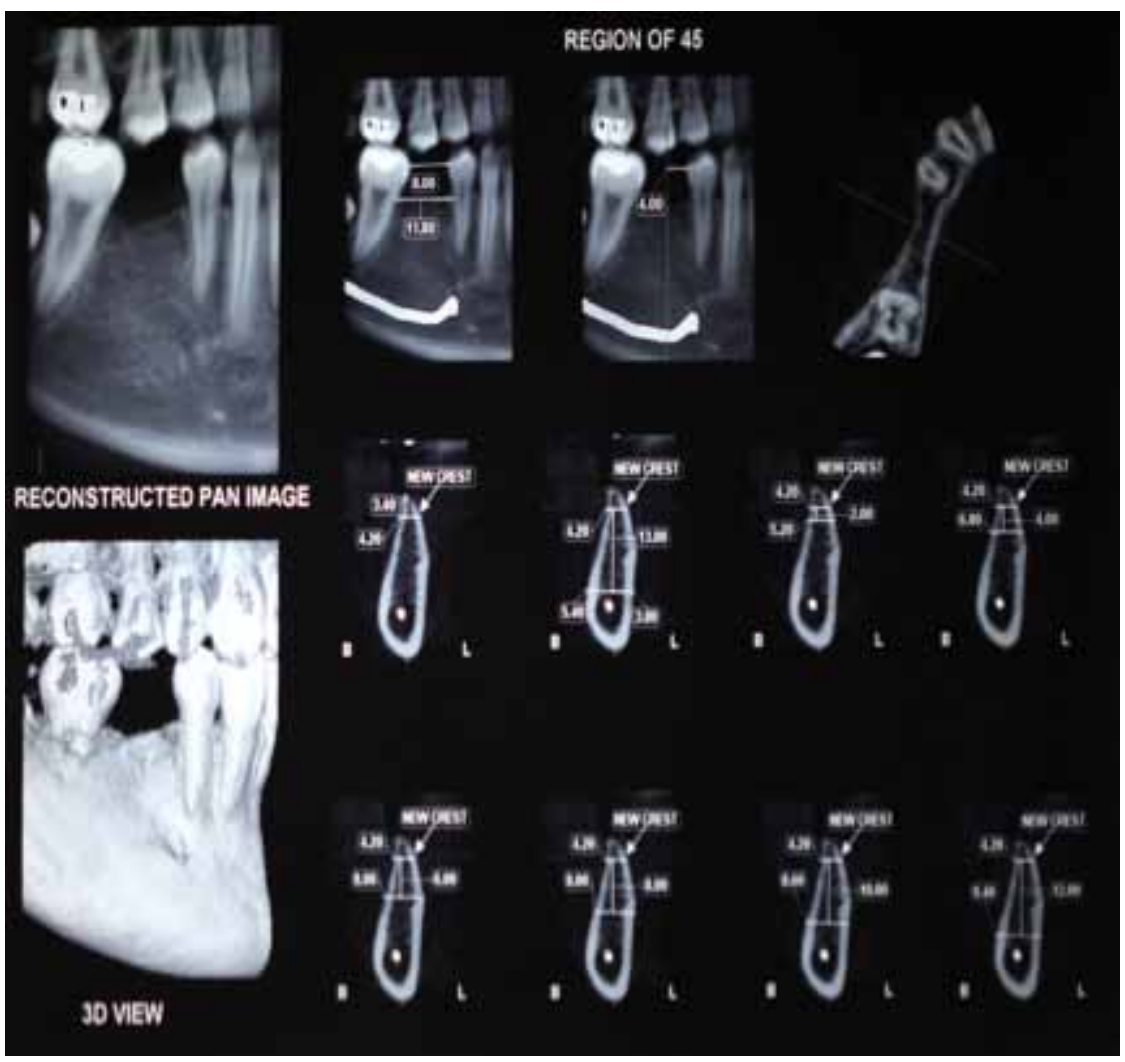

Figure 2: CBCT image used for radiographic examination 


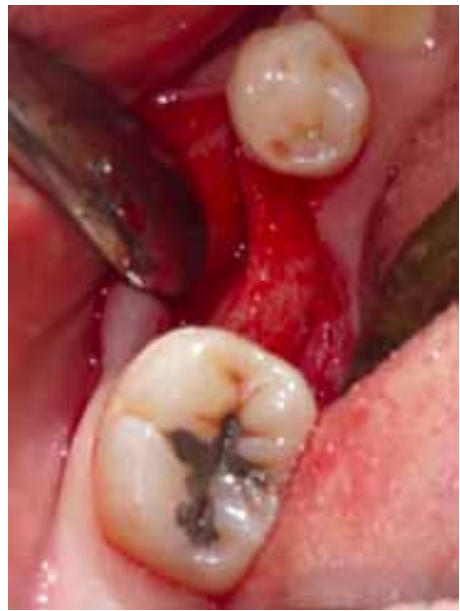

Figure 3: Elevation of a full thickness mucoperiosteal flap buccally and lingually

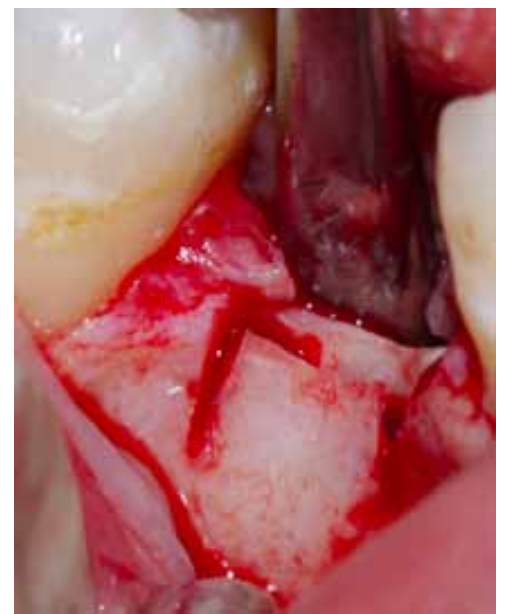

Figure 4: Vertical osteotomy cuts

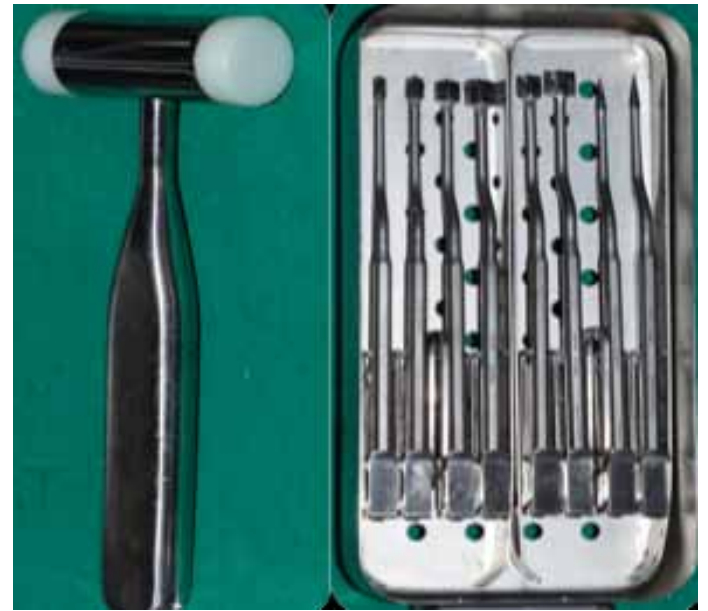

Figure 5: Dentium ridge split kit

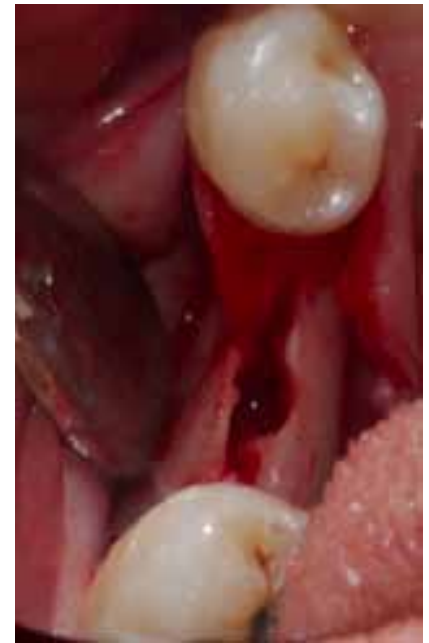

Figure 6: Expanded ridge with widened implant bed

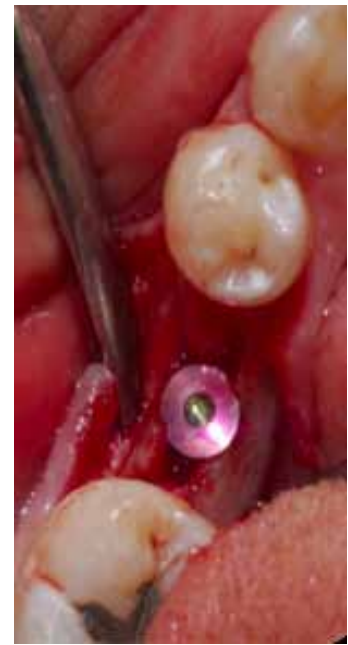

Figure 7: MIS 7 implant placement

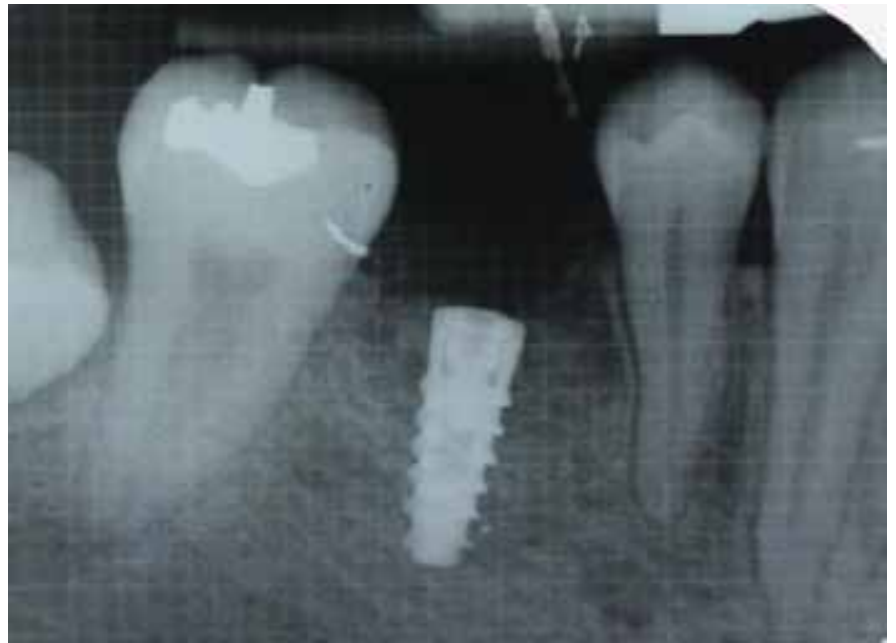

Figure 8: IOPA radiograph immediate post op

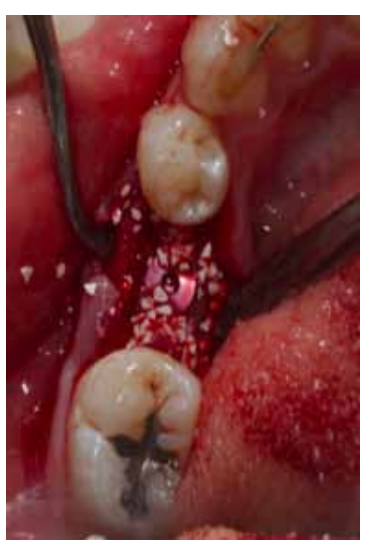

Figure 9: GBR with Bio oss Xenograft material

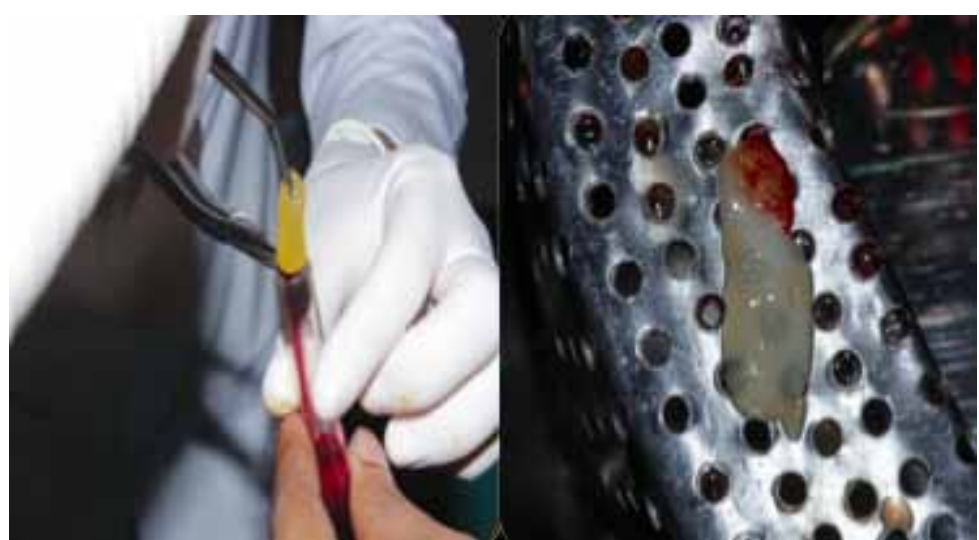

Figure 10: Platelet Rich Fibrin (PRF) membrane

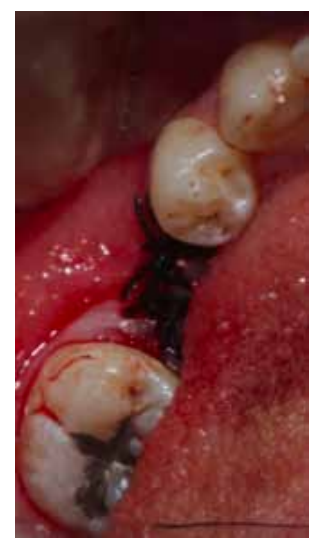

Figure 11: Simple interrupted sutures in place 


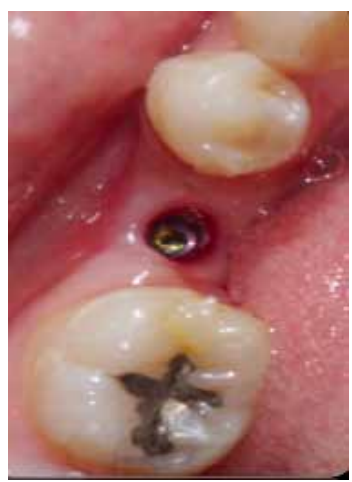

Figure 12: Gingival contours 3 weeks after gingival former placement

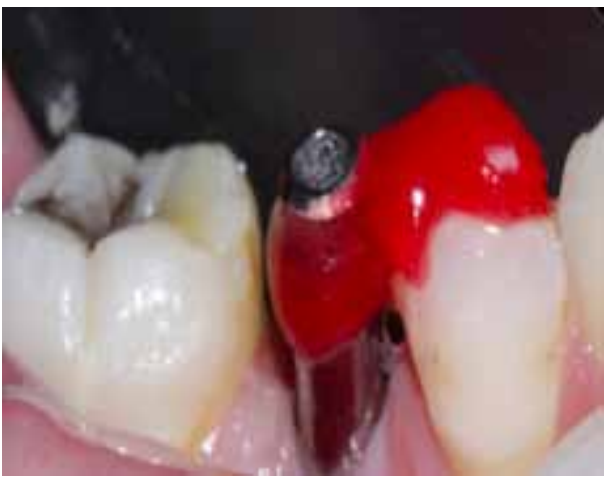

Figure 13: Abutment trial

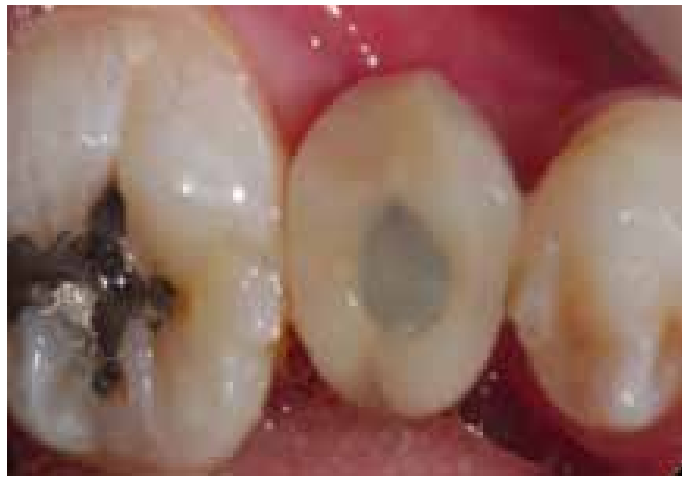

Figure: 14: Screw retained PFM crown

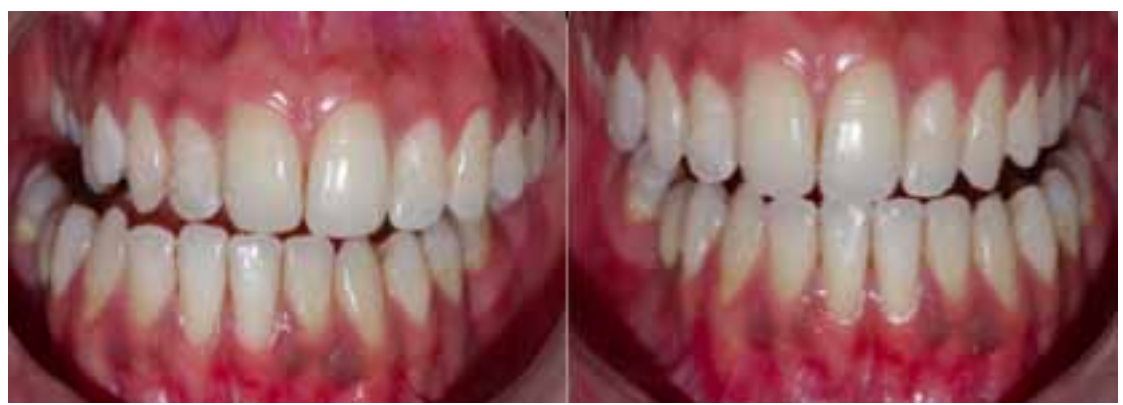

Figure 15: Prosthesis free of eccentric interferences

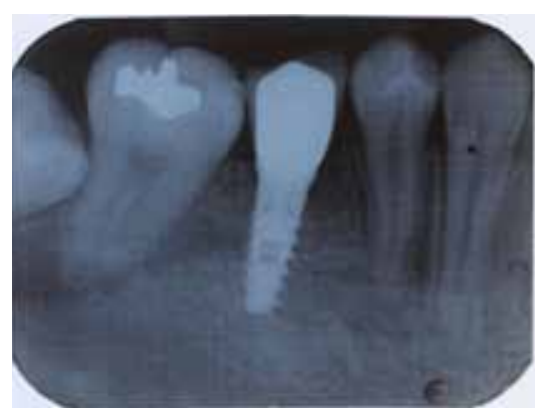

Figure 16: IOPA radiograph 6 months post op.

\section{Discussion}

Horizontal lack of residual ridge width can complicate the implant procedures. Therefore, ridge construction prior to implant placement is a biomechanical requirement. Dr.Tatum inserted $>5000$ maxillary anterior implants using ridge splitting before 1985 wherein, he expanded atrophic ridges $>3 \mathrm{~mm}$ for simultaneous implant placement and augmentation keeping the periosteum intact. ${ }^{18}$ Later, Summers and Scipioniet al. in 1994 revived and published articles on edentulous ridge expansion with $98.8 \%$ implant survival rate for over 5 years. ${ }^{18,19}$ However, in the mandible two additional vertical osteotomy cuts are given because of decreased flexibility of the mandibular buccal cortical plates. ${ }^{16,20}$ Plateletrich fibrin (PRF) derived autogenously from the own blood of the patients in combination with xenografts increase the bone regeneration and accelerate the wound healing due to the presence of various growth factors. ${ }^{21-22}$

Several modifications of the ridge splitting technique have been proposed. Low morbidity, short treatment time and simultaneous implant placement are the advantages over autologous block bone grafting procedures. ${ }^{23} \mathrm{Complications}$ associated with this procedure are rare- fracture of the buccal cortical plate has been reported as a major surgical complication ${ }^{24}$. This can be overcome by controlled force application during the gradual ridge expansion ${ }^{25}$ and thorough pre-operative evaluation of the thickness of the cortical plate and interposed trabecular bone. Also, fabrication of radiographic and surgical guides could prevent improper implant placement. ${ }^{26}$ 


\section{Conclusion}

The ridge splitting technique with simultaneous implant placement seems to be a minimally invasive treatment option for horizontal augmentation of narrow alveolar ridges. As long as thorough preoperative evaluation and a precise surgical and prosthetic protocol are followed predictable clinical results can be achieved.

\section{References}

1. Albrektsson T, Zarb G, Worthington P, Eriksson AR. The long-term efficacy of currently used dental implants: a review and proposed criteria of success. Int J Oral Maxillofac Implants 1986; 1:11-25. [PMID: 3527955]

2. Buser D, Mericske-Stern R, Bernard JP, Behneke A, Behneke N, Hirt HP et al. Longterm evaluation of non-submerged ITI implants. Part 1: 8-year life table analysis of a prospective multi-center study with 2359 implants. Clin Oral Implants Res 1997; 8:161-72. [ DOI: 10.1034/j.1600-0501.1997.080302.x]

3. Lekholm U, Gunne J, Henry P, Higuchi K, Lindén U, Bergström $\mathrm{C}$ et al. Survival of the Brånemark implant in partially edentulous jaws: a 10-year prospective multicenter study. Int $\mathrm{J}$ Oral Maxillofac Implants 1999; 14:639-645. [PMID: 10531735]

4. LeonhardtA, Gröndahl K, Bergström C, Lekholm U. Long- term follow-up of osseointegrated titanium implants using clinical, radiographic and microbiological parameters. Clin Oral Implants Res 2002; 13:127-132.[ https://doi. org/10.1034/j.1600-0501.2002.130202.x]

5. Chiapasco M,AbatiS, RomeoE, VogelG.Clinical outcome of autogenous bone blocks or guided bone regeneration with e-PTFE membranes for the reconstruction of narrow edentulous ridges. Clin Oral Implants Res 1999; 10:27888.[PMID: 10551070DOI: 10.1034/j.16000501.1999.100404.x]

6. Jensen SS and Terheyden H. "Bone augmentation procedures in localized defects in the alveolar ridge: Clinical results with different bone grafts and bone-substitute materials. Int $\mathrm{J}$ Oral Maxillofac Implants
2009;24 Suppl:218-236. [PMID: 19885447]

7. Hammerle $\mathrm{CH}$., et al. "A systematic review of the survival of implants in bone sites augmented with barrier membranes (guided bone regeneration) in partially edentulous patients". J Clin Periodontol 2002;29:22633. [PMID: 12787222 DOI: 10.1034/j.1600051x.29.s3.14.x ]

8. Ignatius AA. A composite polymer/tricalcium phosphate membrane for guided bone regeneration in maxillofacial surgery. J Biomed Mat Res 2001; 88:564-69. [DOI: https://doi. org/10.1002/jbm.1055]

9. M Simion, M Baldoni, D Zaffe. Jaw bone enlargement using immediate implant placement associated with a split-crest technique and guided tissue regeneration. Int $\mathrm{J}$ Periodontics Rest Dent 1992;12:462-73.[ DOI:https://doi. org/10.1016/j.ijom.2016.08.017]

10. Tatum H Jr. Maxillary and sinus implant reconstructions. Dent Clin North Am 1986;30:207-29.[ PMID: 3516738]

11. Bravi F, Bruschi GB, Ferrini F. A 10-year multicenter retrospective clinical study of 1715 implants placed with the edentulous ridge expansion technique. Int $\mathrm{J}$ Periodontics Restorative Dent 2007; 27:557-65. [PMID: 18092450]

12. Suh JJ, Shelemay A, Choi SH, Chai JK. Alveolar ridge splitting: a new microsaw technique. Int $\mathrm{J}$ Periodontics Restorative Dent 2005; 25:165-71. [ PMID: 15839593]

13. Sethi A, Kaus T. Maxillary ridge expansion with simultaneous implant placement: 5-year results of an ongoing clinical study. Int J Oral Maxillofac Implants 2000;15:491-99. [PMID: 10960981]

14. Blus C, Szmukler-Moncler S, Vozza I, Rispoli L, Polastri C. Split-crest and immediate implant placement with ultrasonic bone surgery (piezosurgery): 3-year follow-up of 180 treated implant sites. Quintessence Int 2010;41:463-69. [doi: 10.1111/j.1600-0501.2006.01206.x.]

15. Han JY, Shin SI, Herr Y, Kwon YH, Chung $\mathrm{JH}$. The effects of bone grafting material and a collagen membrane in the ridge splitting technique: an experimental study in dogs. Clin Oral Implants Res 2011;22:1391-98. [PMID: 21435006 DOI: 10.1111/j.16000501.2010.02127.x] 
16. Piccinini M. Mandibular bone expansion technique in conjunction with root form implants: a case report. J Oral Maxillofac Surg 2009;67:1931-36. [https://doi.org/10.1016/j. joms.2009.04.034]

17. Demarosi F, Leghissa GC, Sardella A, Lodi G, Carrassi A. Localised maxillary ridge expansion with simultaneous implant placement: a case series. Br J Oral Maxillofac Surg 2009;47:53540. [PMID: 1915015 DOI: 10.1016/j. bjoms.2008.11.012]

18. Scipioni A, Bruschi GB, Giargia M, Berglundh T, Lindhe J. Healing at implants with and without primary bone contact. An experimental study in dogs. Clin Oral Implants Res 1997;8:3947. [PMID: 9586455 DOI: 10.1111/j.16000501.1997.tb00006.x]

19. Mechery R, Thiruvalluvan N, SreehariAK. Ridge split and implant placement in deficient alveolar ridge: Case report and an update. Contemp Clin Dent 2015;6:94-7. [DOI: 10.4103/0976237X.149300]

20. Enislidis G, Wittwer G, Ewers R. Preliminary report on a staged ridge splitting technique for implant placement in the mandible: a technical note. Int J Oral Maxillofac Implants 2006; 21:445-449. [PMID: 16796289 ]

21. Kökdere NN, Baykul T, Findik Y. The use of platelet-rich fibrin (PRF) and PRF-mixed particulated autogenous bone graft in the treatment of bone defects: An experimental and histomorphometrical study. Dent Res J. 2015;12:418-24. [DOI: 10.4103/17353327.166188]

22. Parhiban PS et al. A contemporary approach for treatment planning of horizontally resorbed alveolar ridge: Ridge split technique with simultaneous implant placement using platelet rich fibrin membrane application in mandibular anterior region. Indian J Dent Res 2017;28:10913.

23. Bassetti MA, Bassetti RG, Bosshardt DD. The alveolar ridge splitting/expansion technique: a systematic review. Clinical Oral Implants Research 2016;27:310-24. [DOI: 10.1111/ clr.12537 ]

24. Chiapasco M, Zaniboni M, Boisco M. Augmentation procedures for the rehabilitation of deficient edentulous ridges with oral implants. Clin Oral Implants Res 2006;17:13659. [DOI: 10.1111/j.1600-0501.2006.01357.x]

25. Sohn DS, Lee HJ, Heo JU, Moon JW, Park IS, Romanos GE. Immediate and delayed lateral ridge expansion technique in the atrophic posterior mandibular ridge. J Oral Maxillofac Surg 2010;68:2283-90. [DOI: 10.1016/j. joms.2010.04.009 ]

26. Papathanasiou. Ridge Splitting Technique for Horizontal Augmentation and Immediate Implant Placement. Balk J Dent Med 2014;18:4147. [DOI: 10.1515/bjdm-2015-0007 ] 